\title{
EDUCACIÓN A DISTANCIA PARA EL SALTO ACADÉMICO - PARTE
}

\section{Enrique Ferroni, Hernando Velásquez y Luz Mary Chavarro.}

\section{INTRODUCCIÓN}

En la primera parte ${ }^{1}$ del presente artículo, la información permite inferir la importancia de la educación a distancia, no solo desde el desarrollo tecnológico y, por ende, de la superación de algunas barreras de carácter técnico, sino por la necesidad de aumentar la cobertura en educación superior con calidad en nuestro país. Se dibujó la directriz en lo que a temáticas compete y se ubicaron dichas temáticas geográficamente en el territorio nacional, a través de polos de desarrollo, cadenas productivas y clusters, reconociendo la posibilidad de movilidad para el estudiante en el concierto internacional.

Es importante resaltar que el estudio no se limita a la educación a distancia, puesto que el análisis está centrado en la educación superior, en general, tanto en el

\section{RESUMEN}

El conocimiento de temáticas y programas por desarrollar en una institución académica, son parte de la base y materia prima para la venta e inserción de procesos educativos, pero no implican, por sí solos, suficiente conocimiento para llevar a cabo un proyecto de las magnitudes que representa la educación a distancia en nuestro país. Es preciso conocer, entre otros aspectos, la correlación entre la disciplina y las necesidades de la región donde se ofrecerá el servicio, la percepción que de este fenómeno tiene la población de esas regiones y la población misma en sus hábitos, preferencias, características y posibilidades.

\section{PALABRAS CLAVE}

Asincronía, polos de desarrollo, cadena de formación, posgrado, ciclos propedéuticos, potencial, ciudades, pregrado, correlación, profesional, demanda, remoto, distancia, sincro- nía, ejes, target, empleo, técnico profesional, formación dual, tecnólogo, georeferenciación, telemática, innovación, temáticas, mercados, tendencia, modalidad, valores, muestra, virtualidad, oferta, zonas de influencia, poblaciones.

\section{ABSTRACT}

The knowledge of themes and programs to be developed by an academic institution are part of the foundation and raw material for the sale and insertion of educational processes, but do not imply, by themselves, sufficient knowledge to successfully attempt a project of the magnitude which distance learning represents in our country.

It is necessary to know, among other aspects, the correlation between the discipline and needs of the region where the service will be offered, the perception the inhabitants of these regions have of this phenomenon, and the population itself in its habits, preferences, characteristics and possibilities.

1. Revista Poliantea No 4. Fundación Politécnico Grancolombiano. Marzo de 2006. 
ámbito nacional como internacional, en la presencialidad así como en la distancia y en las tendencias que marcan las especialidades acordes con la demanda laboral. Desde tal óptica el lector debe considerar esta segunda parte.

Aquí se definen, a partir de diferentes criterios de selección como la tendencia, la implicación tecnológica, la vocación y otros, los programas que se extractan del abanico obtenido en el análisis de oferta nacional e internacional, en la modalidad presencial y a distancia, ya bajo el concepto de ciclos propedéuticos o cadenas de formación.

Finalmente, y dado que hasta el momento se ha desarrollado el análisis de la educación a distancia en función de la oferta, en esta segunda parte se podrá conocer, mediante algunas gráficas comentadas y conclusiones de un estudio del potencial de mercado realizado para este efecto, la capacidad de demanda segmentada por necesidades del mercado laboral y en concordancia con los ejes regionales de desarrollo.

\section{RESEÑA DE AUTOR}

La dirección del equipo de educación a distancia está a cargo de Enrique Ferroni Guzmán, administrador de empresas, egresado del Politécnico y quien se ha desempeñado en la Vicerrectoría de Programas Especiales de la Institución a lo largo de diez años, ocho de ellos en el Departamento de Formación Empresarial.

Hernando Velásquez Montoya, Coordinador académico especializado en docencia universitaria tiene 20 años de experiencia en educación a distancia.

Luz Mary Chavarro Porras, Asesora pedagógica especializada en mercadeo y publicidad. Cuenta con 15 años de experiencia en diseño curricular por competencias y virtualización de contenidos.

\section{PROPUESTA DE PROGRAMAS EN CADENA DE FORMACIÓN}

Como resultado del análisis de la oferta educativa y considerando las variables de la investigación ${ }^{2}$, se resaltaron 29 temáticas que constituyen una amplia y variada oferta educativa, máxime si se tiene en cuenta que se desarrollarían en cadena de formación (técnico profesional, tecnólogo y profesional), lo que representaría 87 programas de pregrado, la mayoría susceptibles de extenderse a una especialización.

Pero estudiar el mercado para indagar la demanda potencial de nueve temáticas de las 87 definidas, implicó georeferenciar las áreas con mayor correlación entre los ejes de desarrollo de las regiones y las temáticas propuestas (ver tabla 1).

De esta manera se inició un proceso de reducción de las temáticas y las zonas para extractar las más preponderantes por la conveniencia de definir un mercado en términos de necesidad y vocación de la región, como ya se mencionó, y por los costos que representaría no centrarse en ubicaciones concretas (ver tabla 2):

2 Vocación institucional, tendencias científicas y tecnológicas nacionales e internacionales, necesidades empresariales, vocaciones regionales por polos de desarrollo, convenios de competitividad y planes estratégicos de gobierno (en Revista Poliantea $\mathrm{N}^{\circ}$ 4. Fundación Politécnico Grancolombiano. Marzo de 2006, "Educación a Distancia para el Salto Académico", Primera Parte). 
Tabla 1. Georeferenciación de programas

\begin{tabular}{|c|c|c|}
\hline PROGRAMA & REGIONES PROPICIAS PARA DESARROLLO DE PROGRAMAS & EJES DE DESARROLLO DE LAREGIÓN \\
\hline $\begin{array}{l}\text { Ingeniería en Medios } \\
\text { Digitales }\end{array}$ & $\begin{array}{l}\text { Valle del Cauca, Antioquia, Risaralda, } \\
\text { Caldas, Quindío. }\end{array}$ & $\begin{array}{l}\text { Red especializada de tecnologías } \\
\text { de información y comunicación. } \\
\text { Existencia de empresas de base tecno- } \\
\text { lógica, y principales clusters tecnológi- } \\
\text { cos del país. }\end{array}$ \\
\hline Hotelería y Turismo & $\begin{array}{l}\text { Atlántico, Magdalena, Bolívar, Guajira, } \\
\text { Valle del Cauca, Nariño, Quindío, } \\
\text { Cauca, Boyacá, Santanderes, San } \\
\text { Andrés, Providencia, Territorios } \\
\text { Nacionales. }\end{array}$ & $\begin{array}{l}\text { Zonas francas, polos de desarrollo, } 45 \\
\text { parques turísticos del país, clusters. }\end{array}$ \\
\hline Ingeniería Logística & $\begin{array}{l}\text { Atlántico, Magdalena, Bolívar, Guajira, } \\
\text { Valle del Cauca, Nariño, Antioquia, } \\
\text { C/Marca, Risaralda, Caldas, Quindío, } \\
\text { Cauca, Santanderes. }\end{array}$ & $\begin{array}{l}\text { Red especializada de transporte e } \\
\text { internacionalización. Zonas francas } \\
\text { industriales, clusters. }\end{array}$ \\
\hline Gerontología & $\begin{array}{l}\text { Valle del Cauca, Nariño, Antioquia, } \\
\text { C/Marca, Risaralda, Caldas, Quindío, } \\
\text { Cauca. }\end{array}$ & $\begin{array}{l}\text { Red especializada de capital humano, } \\
\text { cadena productiva de servicios de } \\
\text { salud. }\end{array}$ \\
\hline Recursos Humanos & $\begin{array}{l}\text { Atlántico, Magdalena, Bolívar, Valle del } \\
\text { Cauca, Antioquia, C/Marca, Risaralda, } \\
\text { Caldas, Quindío, Tolima, Boyacá, } \\
\text { Santanderes. }\end{array}$ & $\begin{array}{l}\text { Red especializada de capital humano, } \\
\text { principal activo en el desarrollo de las } \\
\text { empresas. }\end{array}$ \\
\hline $\begin{array}{l}\text { Ingeniería en } \\
\text { Diseño de Productos }\end{array}$ & $\begin{array}{l}\text { Atlántico, Magdalena, Bolívar, Valle del } \\
\text { Cauca, Antioquia, C/Marca, Risaralda, } \\
\text { Caldas, Quindío, Tolima, Boyacá, } \\
\text { Santanderes. }\end{array}$ & $\begin{array}{l}\text { Red especializada de internacionaliza- } \\
\text { ción, cubre la totalidad de cadenas pro- } \\
\text { ductivas, clusters, polos de desarrollo. }\end{array}$ \\
\hline Desarrollo de la infancia & $\begin{array}{l}\text { Valle del Cauca, Nariño, Antioquia, } \\
\text { C/Marca, Risaralda, Caldas, Quindío, } \\
\text { Cauca. }\end{array}$ & $\begin{array}{l}\text { Red especializada de capital humano, } \\
\text { cadena productiva de servicios de } \\
\text { salud. }\end{array}$ \\
\hline Banca y Seguros & $\begin{array}{l}\text { Atlántico, Magdalena, Bolívar, Córdoba, } \\
\text { Sucre y Cesar, Valle del Cauca, Nariño, } \\
\text { Antioquia, Risaralda, Caldas, Quindío, } \\
\text { Boyacá, Santanderes. }\end{array}$ & $\begin{array}{l}\text { Red especializada de finanzas, cubre la } \\
\text { totalidad de convenios de competiti- } \\
\text { vidad de las cadenas productivas y los } \\
\text { clusters. }\end{array}$ \\
\hline Ingeniería Financiera & $\begin{array}{l}\text { Atlántico, Magdalena, Bolívar, Córdoba, } \\
\text { Cesar y Sucre, Valle del Cauca, Nariño } \\
\text { Antioquia, Risaralda, Caldas, Quindío, } \\
\text { Boyacá, Santanderes. }\end{array}$ & $\begin{array}{l}\text { Red especializada de finanzas, cubre la } \\
\text { totalidad de convenios de competiti- } \\
\text { vidad de las cadenas productivas y los } \\
\text { clusters. }\end{array}$ \\
\hline
\end{tabular}

Posteriormente, se procedió a filtrar la oferta a través de las recomendaciones del departamento de Planeación y Estadística del Politécnico Grancolombiano, el cual tuvo a su cargo una investigación de carácter similar; y a seleccionar así las tres regiones más preponderantes y los nueve programas más representativos. 
Tabla 2. Otros criterios para la reducción de la oferta

\begin{tabular}{|c|c|c|c|}
\hline REGIONES & PRogramas & PLANEACIÓN RECOMIENDA & EAD RECOMIENDA \\
\hline \multirow{8}{*}{$\begin{array}{l}\text { No. } 1 \text { Región Andina } \\
\text { Bogotá, C/marca, } \\
\text { Boyacá y Santanderes. }\end{array}$} & Recursos Humanos & \multicolumn{2}{|c|}{ Recursos Humanos } \\
\hline & Ingeniería Logística & & Ingeniería Logística \\
\hline & Hotelería y Turismo & & Hotelería y Turismo \\
\hline & Diseño de Productos & \multicolumn{2}{|c|}{ Diseño de Productos } \\
\hline & Desarrollo de la Infancia & \multicolumn{2}{|c|}{ Desarrollo de la Infancia } \\
\hline & Banca y Seguros & & \\
\hline & Ingeniería Financiera & & \\
\hline & Gerontología & & \\
\hline No. 2 Región Pacífica & Recursos Humanos & \multicolumn{2}{|c|}{ Recursos Humanos } \\
\hline $\begin{array}{l}\text { Cauca y Valle del } \\
\text { Cauca }\end{array}$ & Ingeniería Logística & & Ingeniería Logística \\
\hline \multirow{8}{*}{$\begin{array}{l}\text { No. } 3 \\
\text { Región Andina } \\
\text { Eje Cafetero. }\end{array}$} & Hotelería y Turismo & & Hotelería y Turismo \\
\hline & Diseño de Productos & \multicolumn{2}{|c|}{ Diseño de Productos } \\
\hline & Desarrollo de la Infancia & \multicolumn{2}{|c|}{ Desarrollo de la Infancia } \\
\hline & $\begin{array}{l}\text { Ingeniería en Medios } \\
\text { Digitales }\end{array}$ & & $\begin{array}{l}\text { Ingeniería en Medios } \\
\text { Digitales }\end{array}$ \\
\hline & Banca y Seguros & & \\
\hline & Mercadeo Internacional & & \\
\hline & Ingeniería Financiera & & \\
\hline & Gerontología & & \\
\hline No. 4 Región Caribe & Recursos Humanos & \multicolumn{2}{|c|}{ Recursos Humanos } \\
\hline Atlántico, Magdalena & Ingeniería Logística & & Ingeniería Logística \\
\hline y Bolívar. & Hotelería y Turismo & & Hotelería y Turismo \\
\hline
\end{tabular}

De esta manera, hasta el momento se tiene claridad sobre las regiones (principales ciudades y sus áreas de influencia), así como programas recomendables a la luz de los diferentes parámetros definidos.

\section{ESTUDIO DE MERCADO}

Para aprobar o reprobar la hipótesis que sugieren las temáticas y las regiones seleccionadas, esto es, la capacidad de demanda segmentada por necesidades del mercado laboral $\mathrm{y}$ en concordancia con los ejes regionales de desarrollo y, a la vez, para consultar la cifra de demanda potencial del mercado, se diseñó y desarrolló un estudio del mercado potencial.

Con esta información, el equipo de educación a distancia enfoca el estudio en tres regiones y nueve temáticas.

\section{REGIONES}

- Región Andina, con Girardot, Fusagasugá y Zipaquirá como muestras representativas de la región para efectos de la educación a distancia. 
- Región Pacífica, con Cali, Bugalagrande y Candelaria (muestras).

- Región Caribe, con Cartagena, Barran-quillay Santa Marta (muestras).

\section{IEMÁTICAS}

- Ingeniería Logística

- Hotelería y Turismo

- Ingeniería en Diseño de Productos

- Gerontología

- Desarrollo de la Infancia

- Ingeniería en Medios Digitales

- Ingeniería Financiera

- Recursos Humanos

- Banca y Seguros

La investigación de mercados se contrató en la modalidad de outsourcing con la firma Cndamer. Inicia con el diseño del cuestionario para entrevistas directas (investigación cuantitativa), en el cual se consignan los elementos principales para ser indagados.

\section{ANTECEDENTES}

El Politécnico Grancolombiano viene evaluando y analizando el mercado para la poner en marcha el proyecto de Educación a Distancia Virtual, que plantea la cadena de formación para el técnico laboral, técnico profesional, tecnólogo y profesional.

En este proceso de evaluación se han contemplado varios aspectos desde el potencial de las regiones, así como la vocación de las mismas; en concordancia con las necesidades y la orientación del Politécnico, se ha llegado a la preselección de cerca de nueve temáticas susceptibles de ser desarrolladas y se ha decidido, en un principio, el cubrimiento de tres regiones.
Con miras a definir, por una parte el potencial del mercado que actualmente existe, la percepción que se tiene sobre la educación a distancia virtual y las orientaciones (temáticas) de mayor acogida, se precisó la necesidad de adelantar el presente estudio.

Además, el informe escrito incluye información de tipo secundario referente al mercado en términos de oferta, usuarios, orientaciones temáticas y niveles, para su respectivo análisis.

\section{Targetde investigación}

Hombres y mujeres entre los 17 y 35 años, que aspiran a cursar una carrera universitaria, pero que están limitados, bien sea por aspectos de tiempo, económicos, laborales, físicos o la inexistencia del programa de interés pertenecientes a los estratos dos a cuatro, residentes en:

- Bogotá, Girardot, Fusagasugá y Zipaquirá

- Cali, Bugalagrande y Candelaria

- Barranquilla, Cartagena y Santa Marta.

\section{OBJETIVO GENERAL}

Determinar la demanda potencial existente en términos de personas, para el desarrollo del programa Educación a Distancia Virtual que cuente con el respaldo del Politécnico Grancolombiano y precisar las necesidades y actitudes que existen en esta modalidad de educación.

\section{MUESTRA}

Se realizó un total de 1.384 encuestas con la siguiente distribución (ver tabla 3): 
Tabla 3. Distribución de encuestas realizadas

\begin{tabular}{|c|c|c|c|}
\hline & ReGIÓN CENTRO & REGIÓN OCCIDENTE & ReGIÓN NORTE \\
\hline Ciudad capital & 258 & 208 & 213 \\
\hline $\begin{array}{c}\text { Municipio } \\
\text { adicional 1 }\end{array}$ & 99 & 100 & 100 \\
\hline $\begin{array}{c}\text { Municipio } \\
\text { adicional 2 }\end{array}$ & 102 & 99 & 101 \\
\hline $\begin{array}{c}\text { Municipio } \\
\text { adicional 3 }\end{array}$ & 104 & & \\
\hline TOTAL & $\mathbf{5 6 3}$ & $\mathbf{4 0 7}$ & $\mathbf{4 1 4}$ \\
\hline
\end{tabular}

Este planteamiento, en un nivel de confianza del 95\%, permite interpretar resultados con los siguientes márgenes de error:

- Total general

(1.384 encuestas) .$+/-2.6 \%$

- Total región 1

(563 encuestas) $+/-4.1 \%$

- Total región 2 ó 3

(407 encuestas) $+/-4.9 \%$

- Total ciudad capital Región 1

(258 encuestas) $+/-6.1 \%$

- Total ciudad capital Región 2

(208 encuestas) $+/-6.8 \%$

- Total ciudad capital Región 3

(213 encuestas). $+/-6.6 \%$

- Total cada municipio secundario

(100 encuestas) $+/-9.9 \%$

Para la estimación del potencial, este planteamiento obligó a que se aplicaran los respectivos factores de ponderación necesarios por la desproporción que se establece por ciudades / municipios.

La selección de la muestra se hizo en forma totalmente aleatoria, tomando como unidad las cuadras de cada ciudad (polietápico por conglomerado).
RESULIADOS

Es oportuno aclarar que se presentan algunas de las más de 150 gráficas arrojadas por el estudio y seleccionadas para ilustrar el potencial de mercado, aunque las conclusiones no omiten ninguna información.

También es importante aclarar que, dentro de la metodología de la encuesta, se indagó a los encuestados con base en dos premisas:

La primera, de forma espontánea. Es decir, su propia opinión y conocimiento acerca de qué es la educación a distancia, sus ventajas y desventajas, programas que consideran útiles para sus proyectos personales y sus regiones, etc.

En segundo lugar, se presentó la definición de "educación a distancia" como la concibió el Politécnico Grancolombiano; los programas que considera pertinentes para las regiones encuestadas; las ventajas a la luz del diseño que estableció para esta modalidad, etc. Cuando esto ocurre, se habla de "concepto".

Donde aparezca Ingeniería Digital de Arte y Diseño Tridimensional, debe leerse Ingeniería en Medios Digitales. 


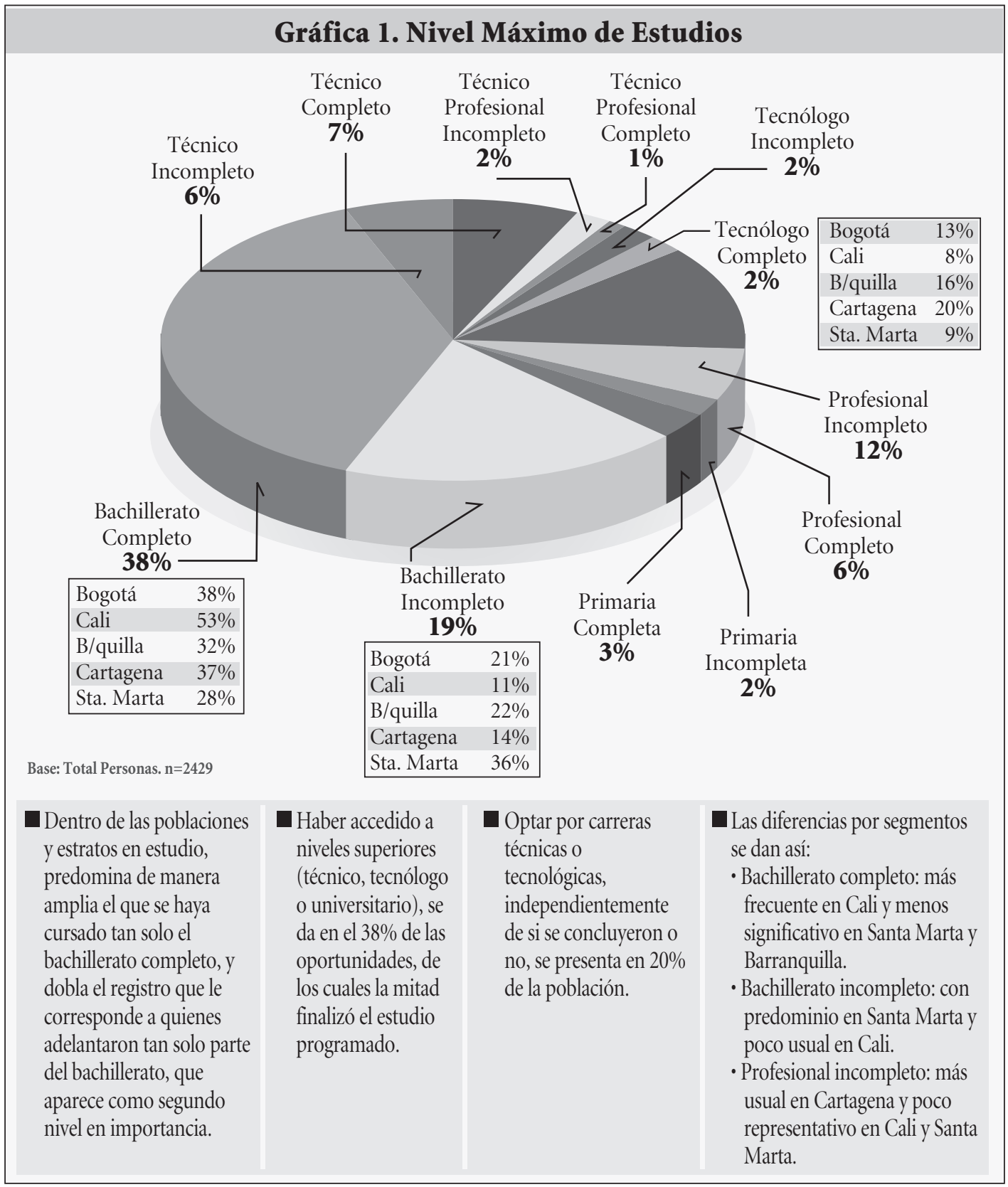




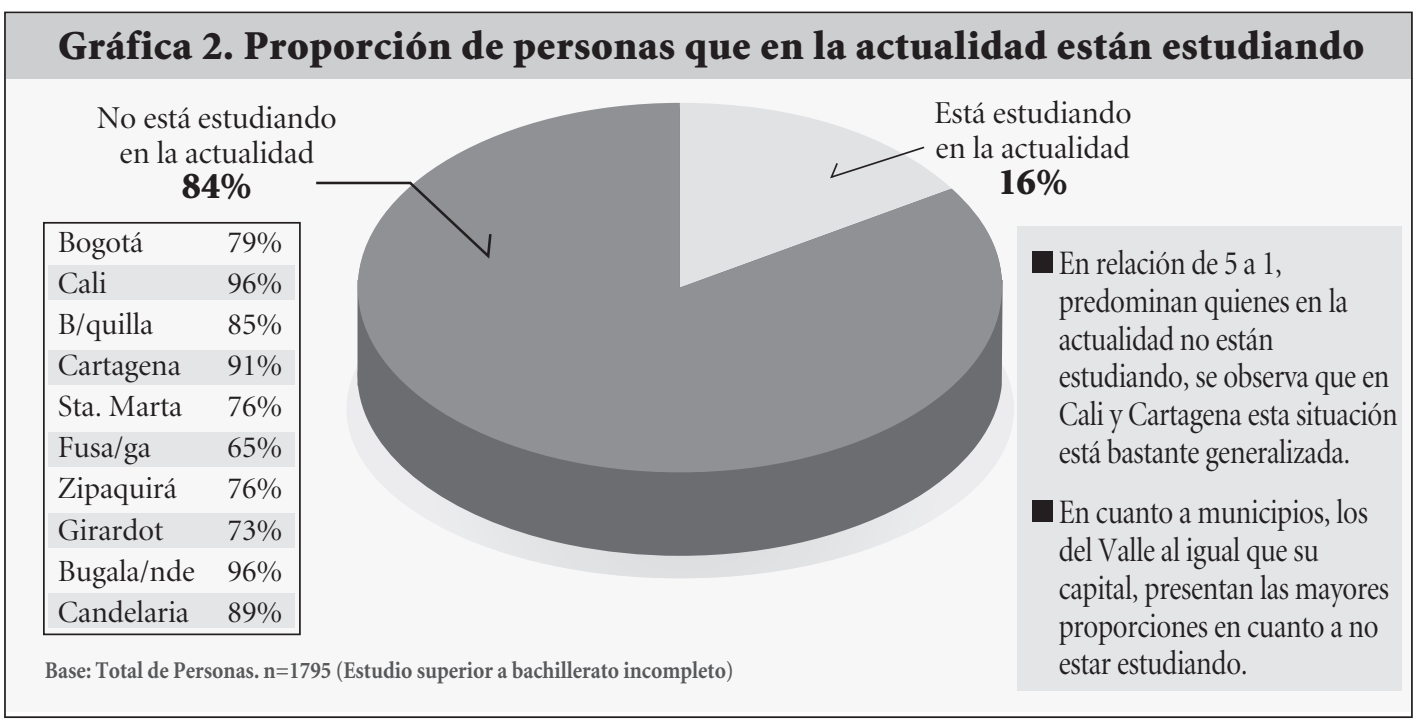

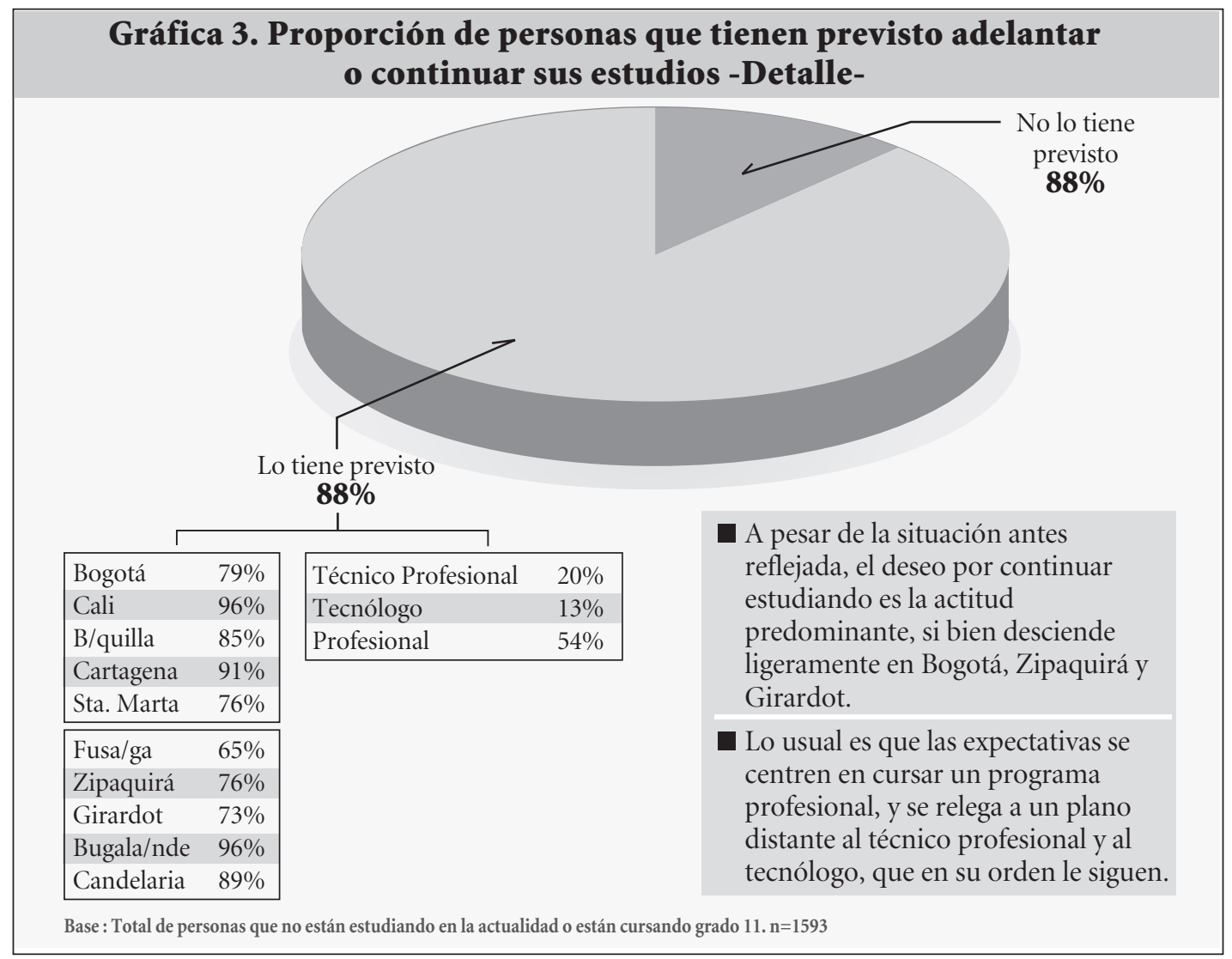




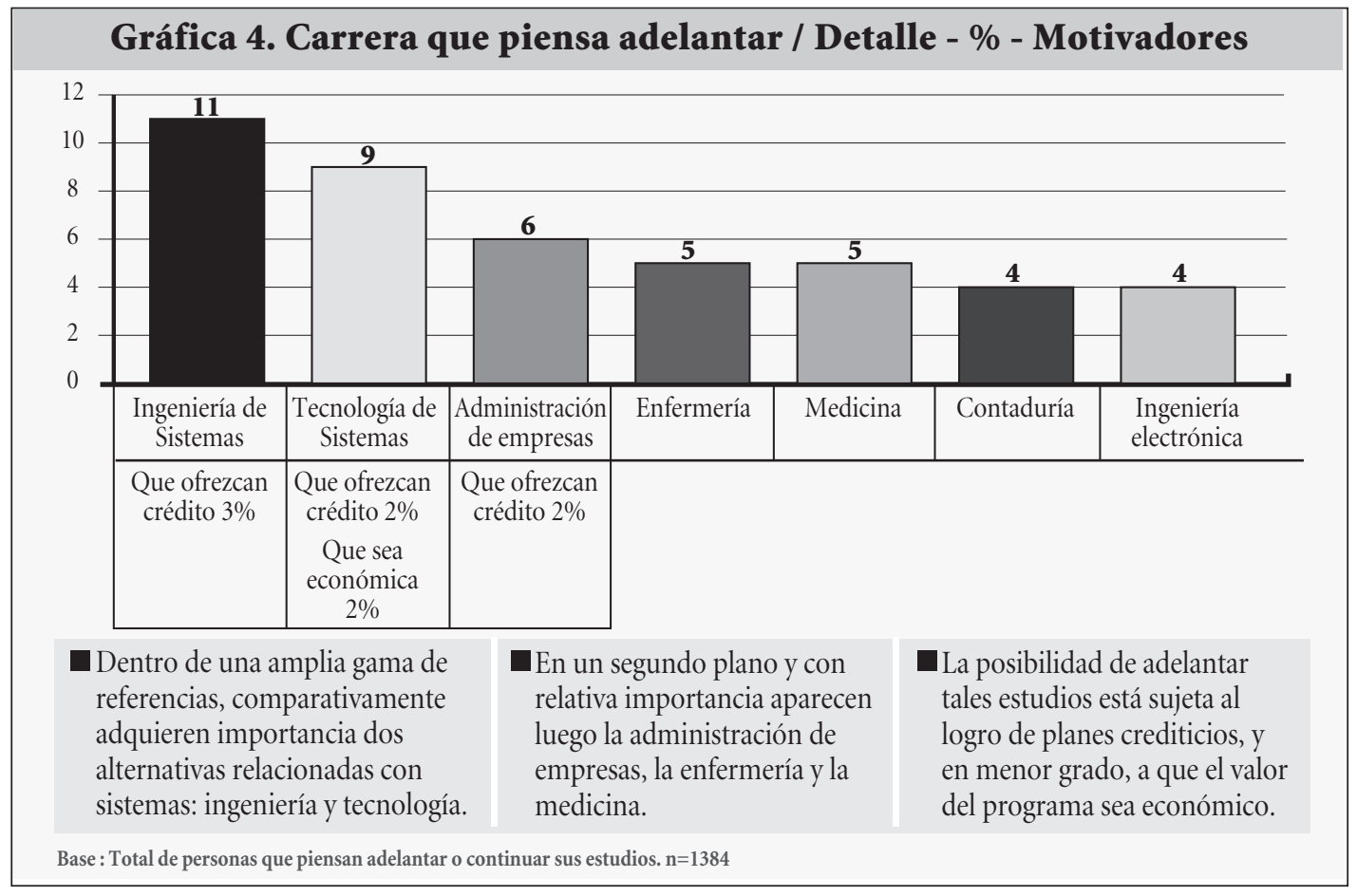

\section{Gráfica 5. Razones por las cuales no ha adelantado hasta el momento el programa que desea - \%}

Tomando ahora a quienes tienen bachillerato completo únicamente (excluyendo a quienes cursan el grado once), su aspiración de continuar estudiando se ha visto afectada en primer grado por el factor económico; sobresale al respecto Bogotá, en contraste con Santa Marta donde esta razón es menos usual.

Como segundo elemento inhibidor aparece luego y distante del primero, la limitante de tiempo. Sobresale Cali en esta ocasión y nuevamente es Santa Marta la plaza donde tal objeción es menos relevante.

Otras alternativas que explican el no haber estudiado, comparativamente pierden importancia.

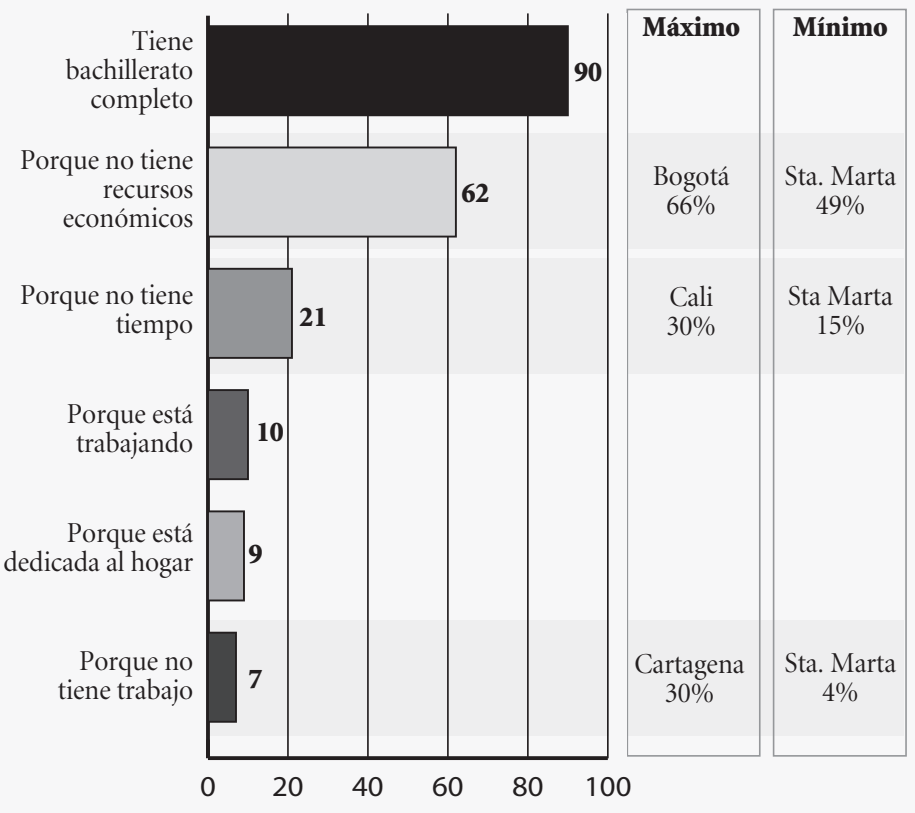

Base: Total de personas que piensan adelantar 0 continuar sus estudios. $\mathbf{n}=1384$ 


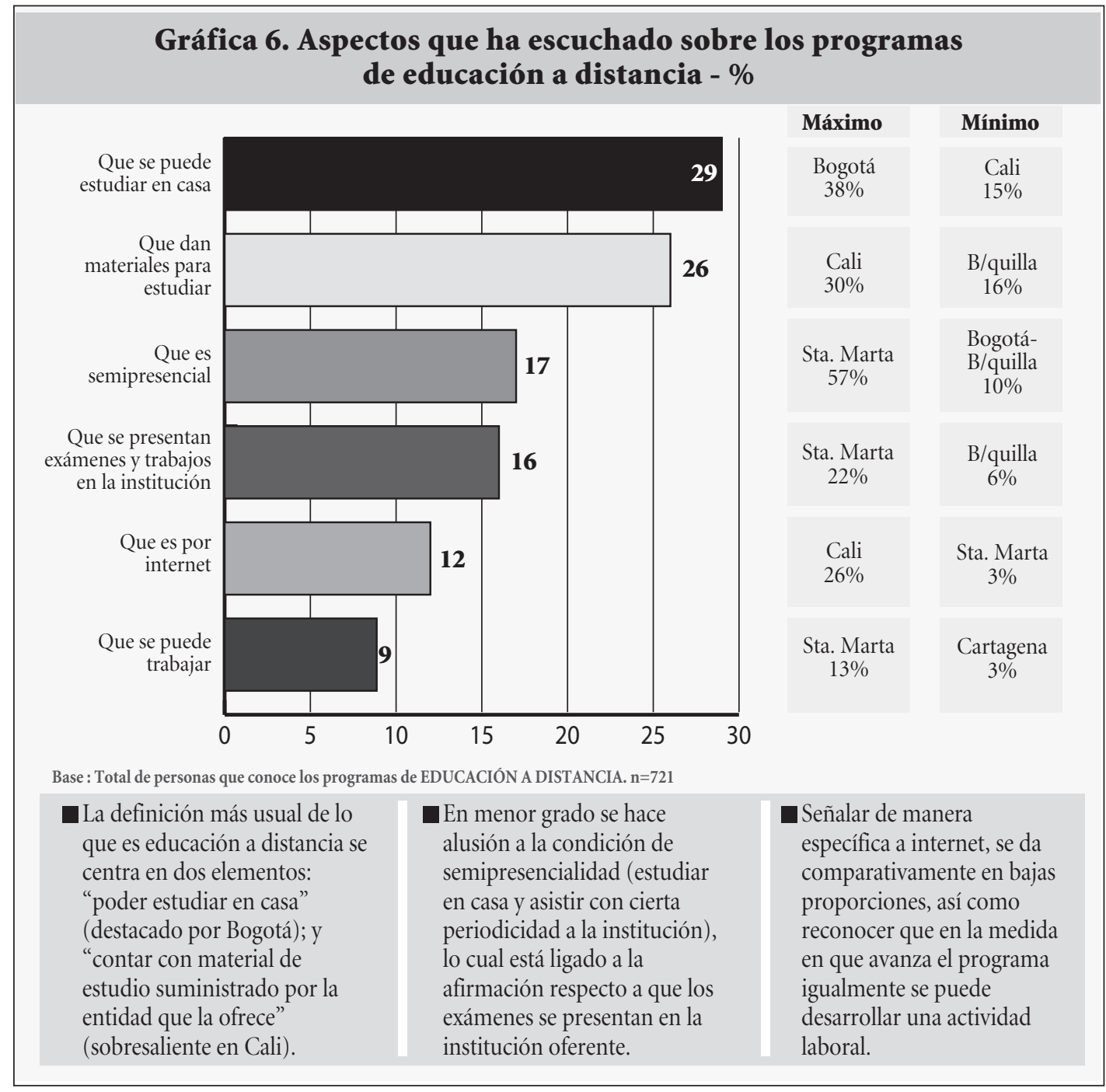




\section{Gráfica 7. Aspectos positivos y negativos atribuidos a la educación a distancia - \%}

Teniendo en cuenta que para la casi totalidad de la población, la modalidad de educación a distancia implica aspectos positivos, los principales señalamientos se centran en poder trabajar paralelamente, ahorrar tiempo y no tener que salir de casa.

En el lado opuesto, es decir en cuanto a debilidades que en conjunto se citan en alta proporción, se cuestiona el no contar con un tutor que oriente o explique lo que no se ha comprendido.

Conviene señalar que esta última inquietud es determinante en la ciudad de Cali, mientras que pierde relieve en Santa Marta.

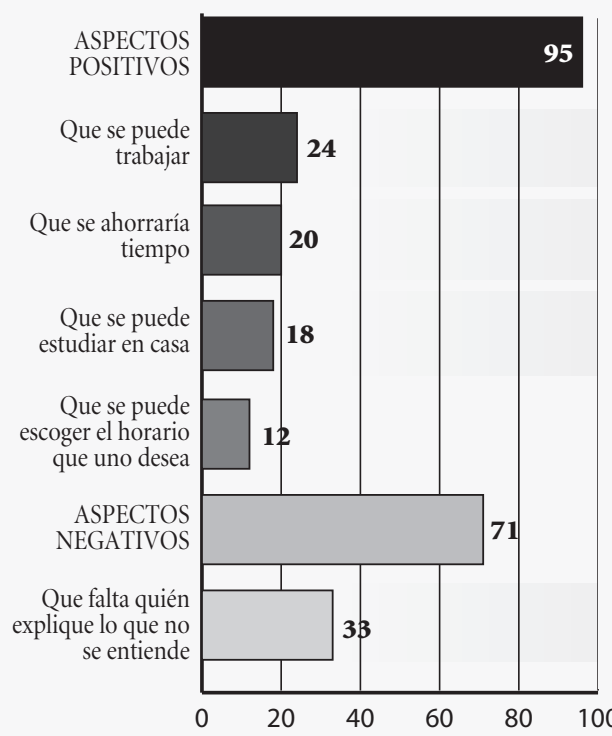

Máximo

Mínimo

Sta. Marta Cali $30 \%$

$14 \%$

$\begin{array}{cc}\text { Bogotá } & \text { Cartagena } \\ 29 \% & 8 \%\end{array}$

Cartagena Sta. Marta $25 \% \quad 9 \%$

Cali Sta. Marta

$44 \% \quad 13 \%$

\section{Gráfica 8. Ventajas y desventajas de la educación a distancia frente a la alternativa de educación presencial - \%}

Al igual que en la evaluación individual, al establecer el comparativo respecto a la modalidad presencial, casi la totalidad de la población bajo estudio reconoce bondades de la primera sobre la segunda, se hace énfasis una vez más en la posibilidad de trabajar paralelamente y en este sentido contar con más tiempo para el trabajo; adicionalmente se le abona el poder definir de manera personal el horario de estudio.

- Respecto a las críticas, una vez más adquiere marcada importancia no poder contar con la orientación de una persona que aclare dudas o inquietudes.

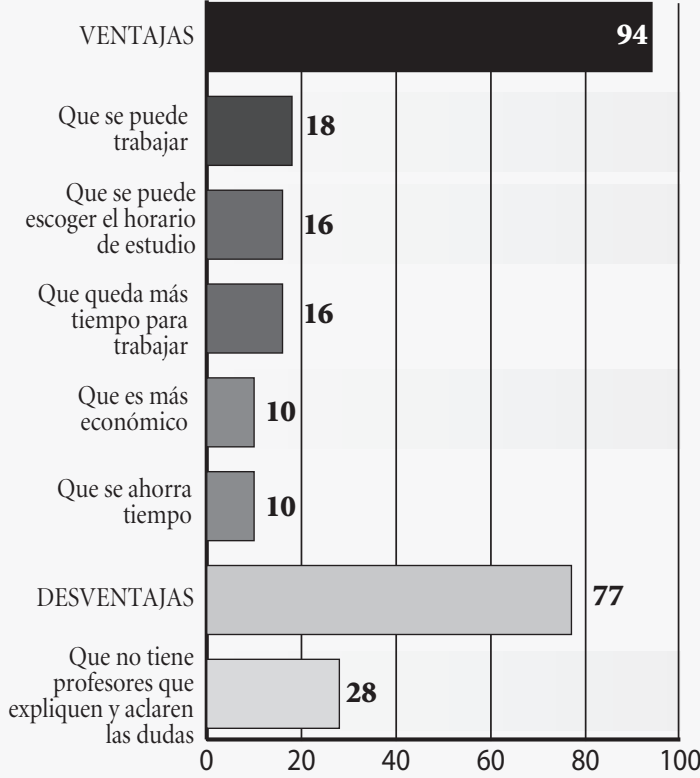

Máxim

Sta. Marta B/quilla $34 \% \quad 14 \%$

Cali Sta. Marta $26 \% \quad 6 \%$

Bogotá Sta. Marta $13 \% \quad 1 \%$

Cali Sta. Marta $33 \% \quad 17 \%$ 


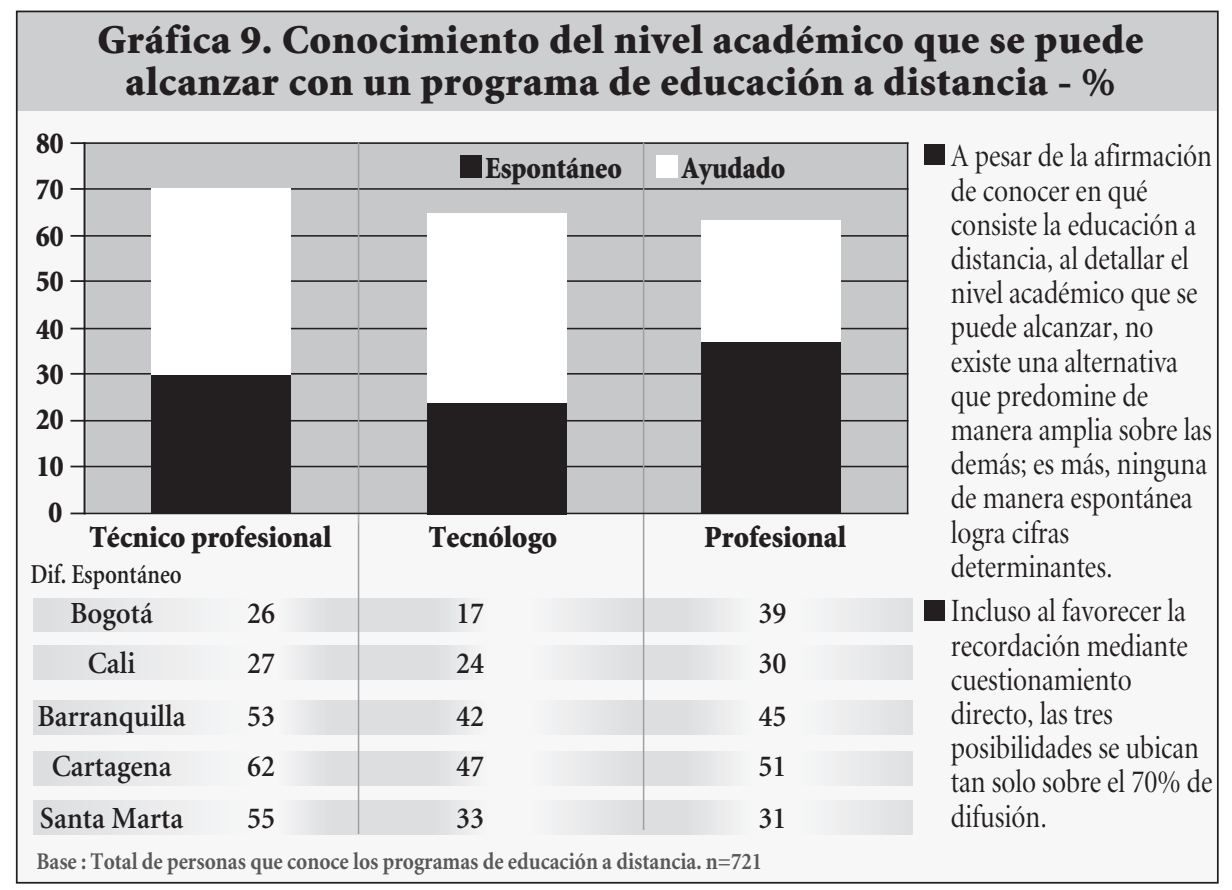

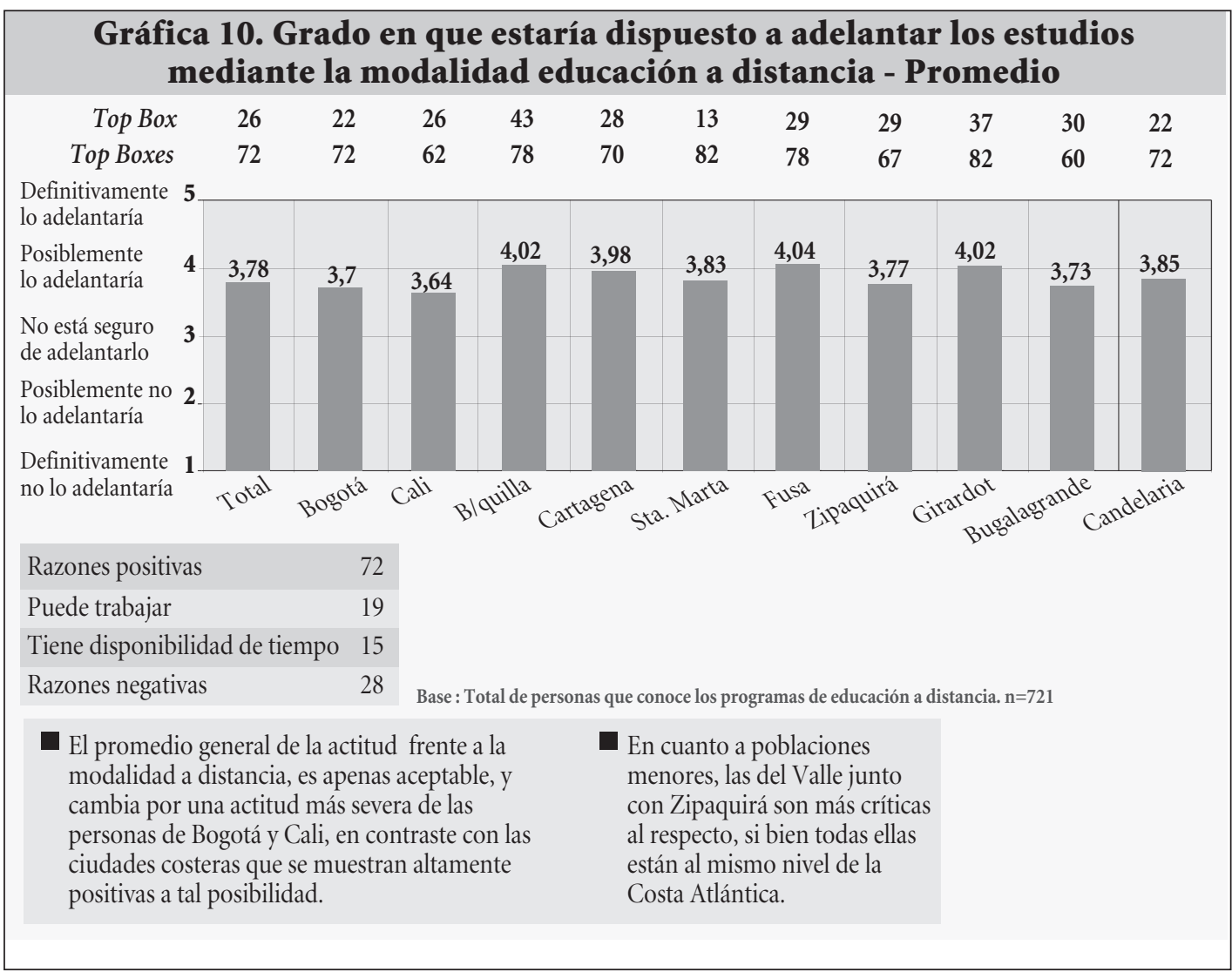




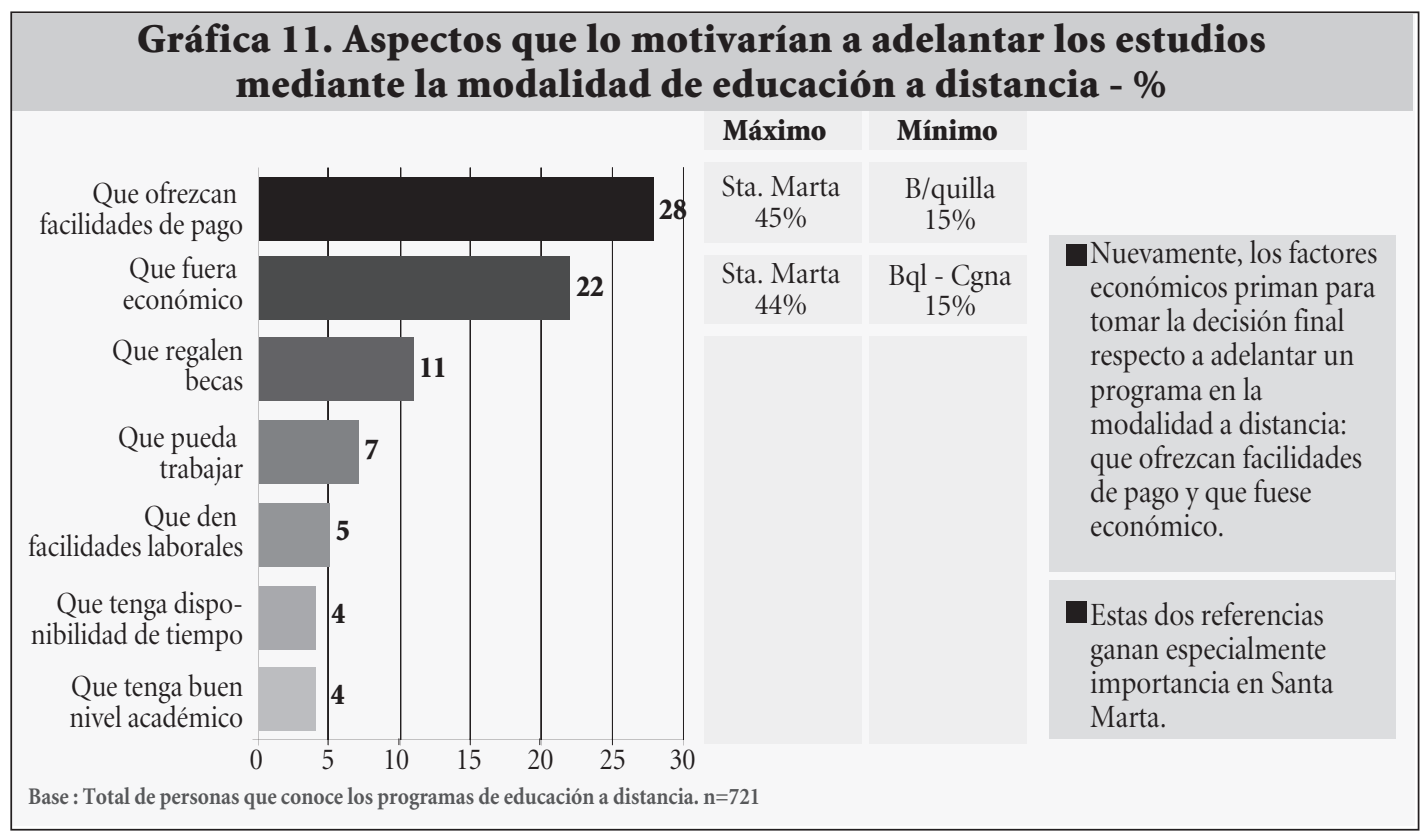

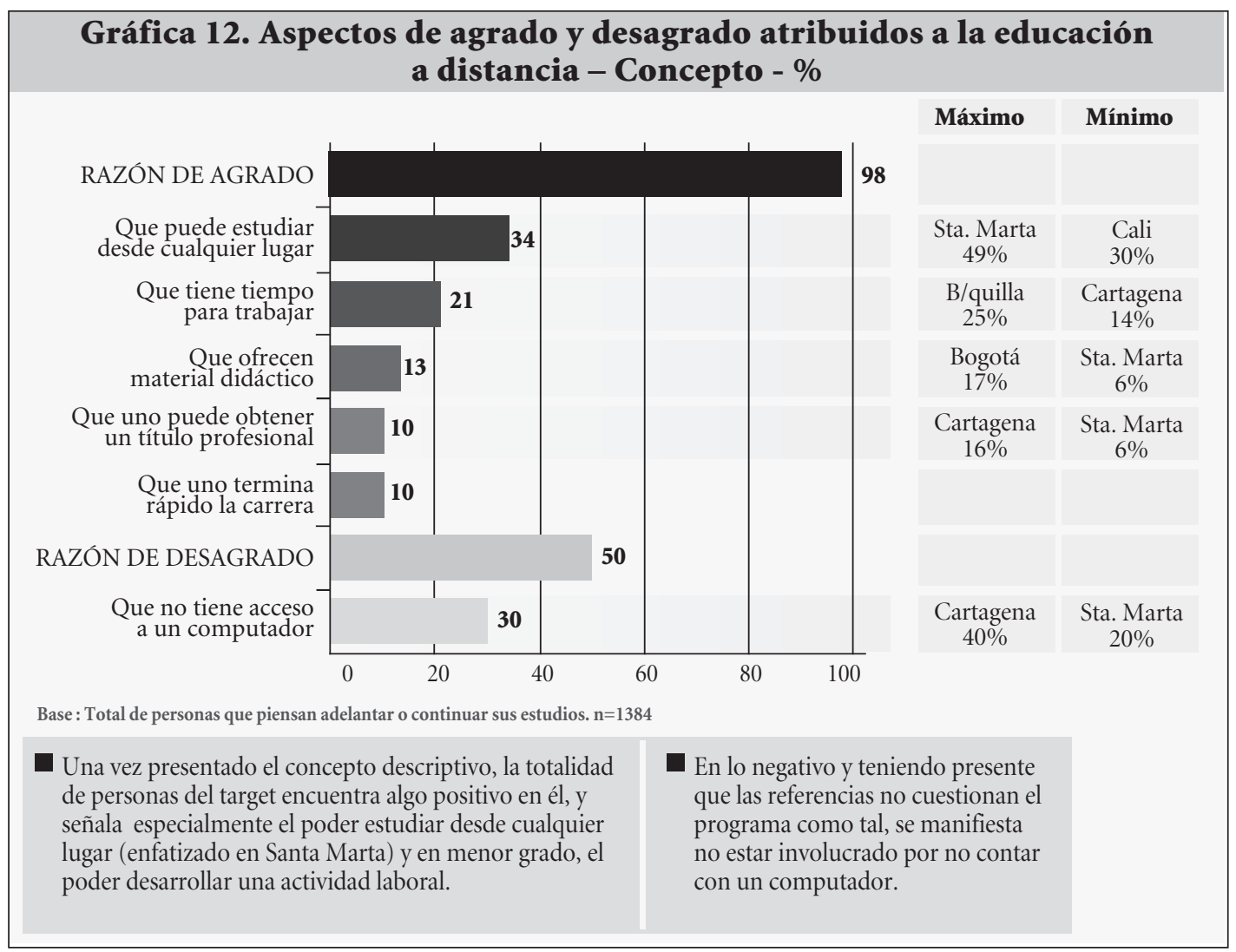




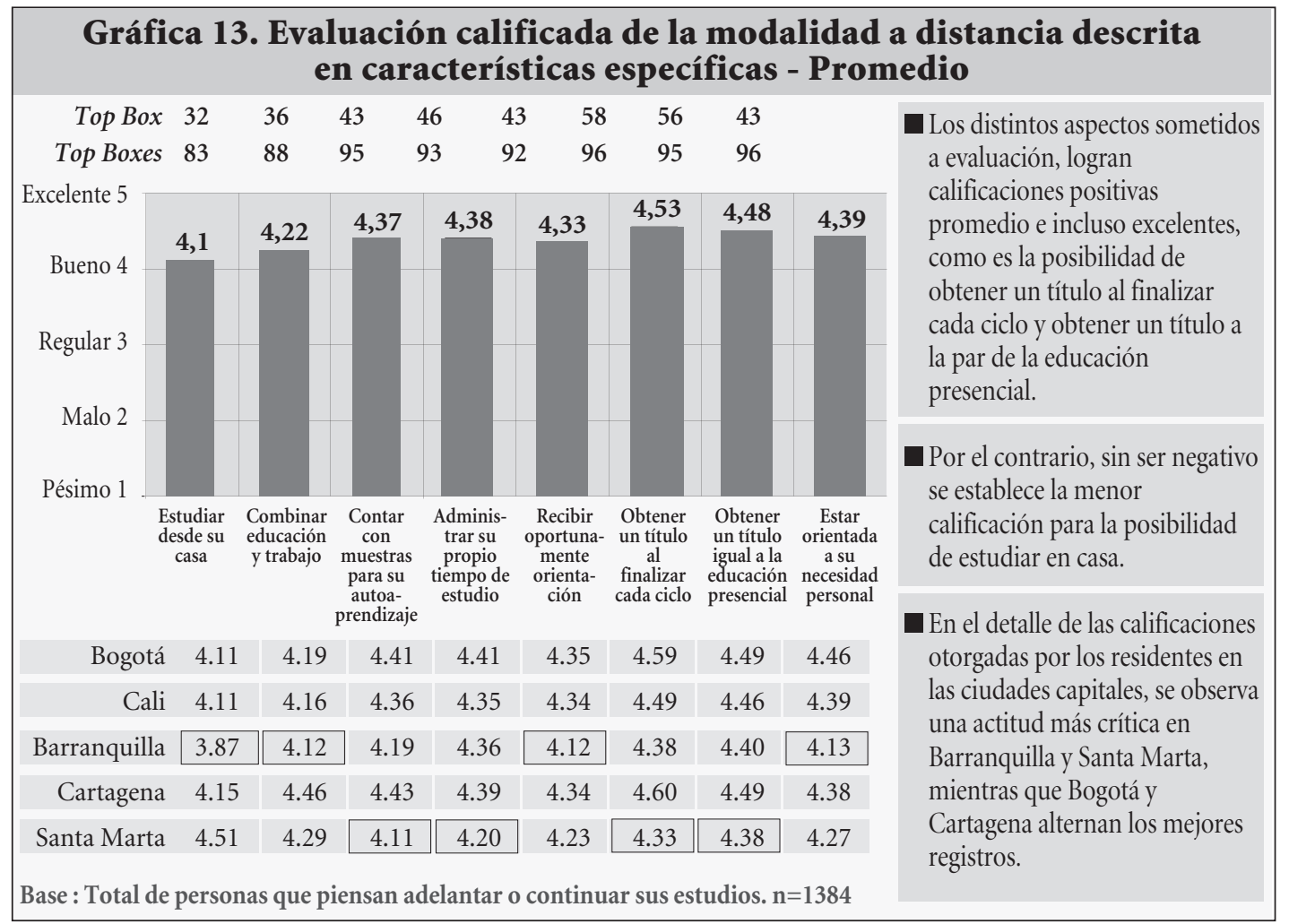

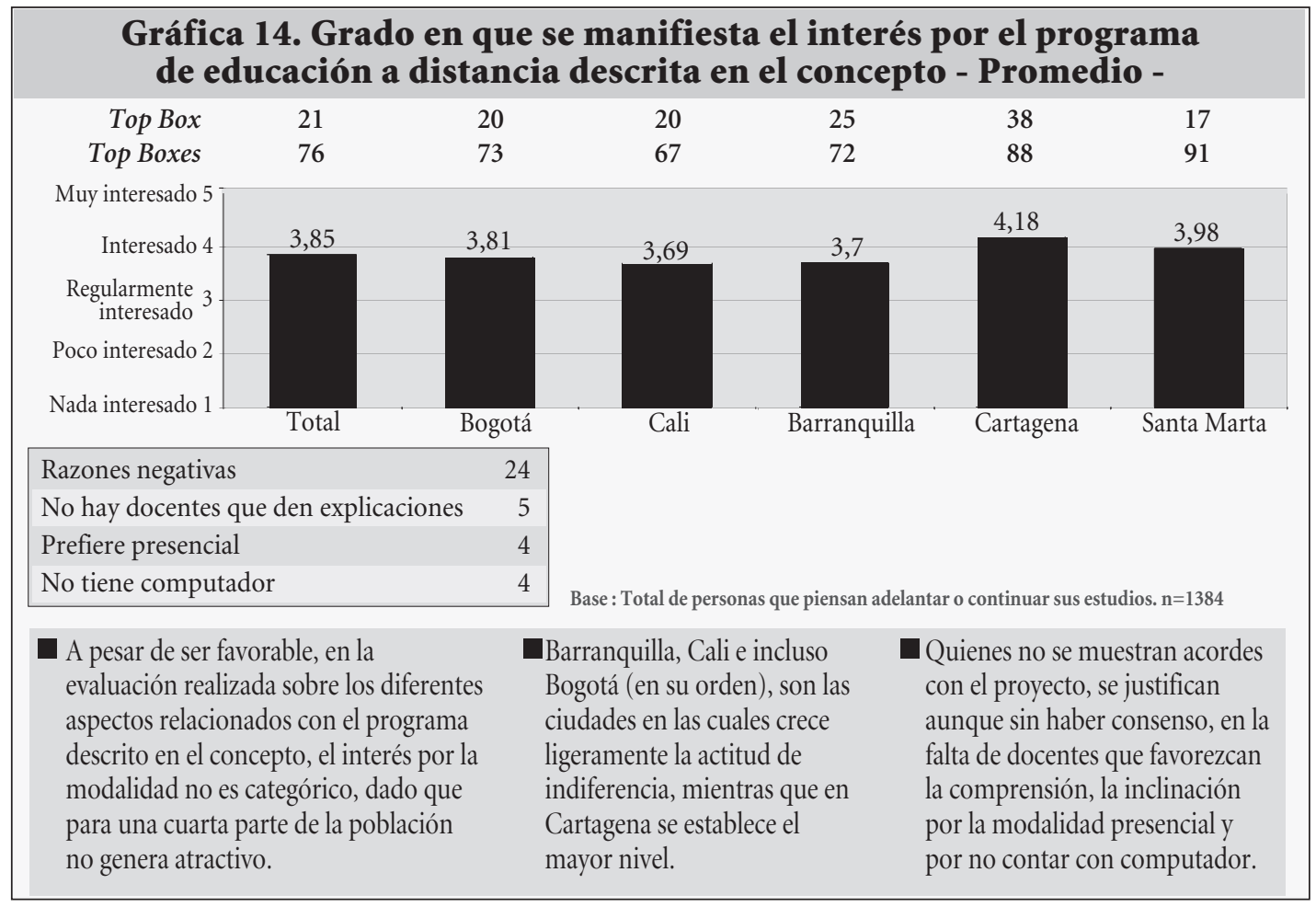




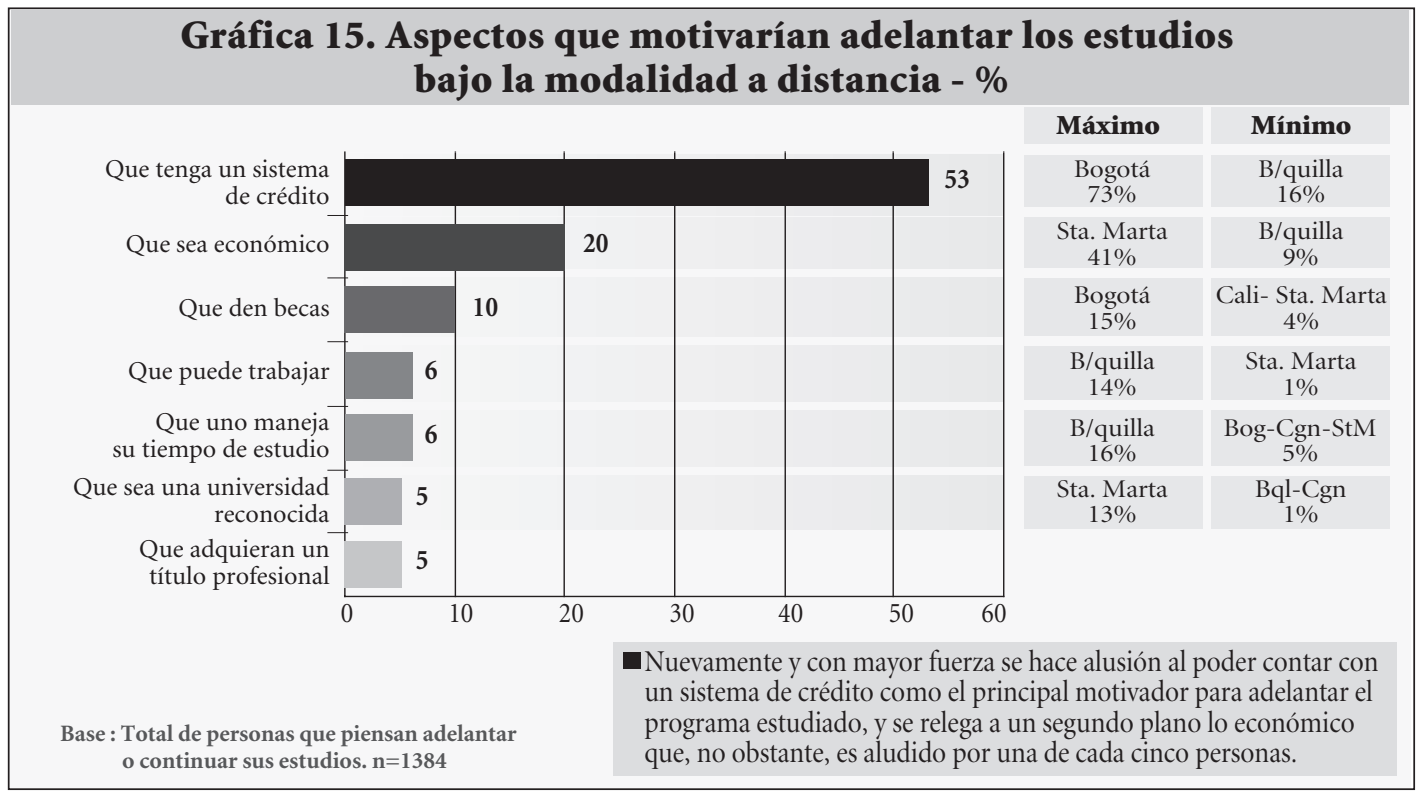

\section{Gráfica 16. Grado en que se considera interesante cada programa - Promedio}

- De las alternativas planteadas que logran despertar mayor interés son: Recursos

Humanos, Ingeniería Digital de Arte y Diseño Tridimensional, y Desarrollo de la Infancia; a cambio, las que al parecer revisten menor atractivo son: Gerontología y, Banca y Seguros. (conceptos), las

Top Box 13

Top Boxes 56

22

60

14

12

27

$65 \quad 67$

$\begin{array}{rrrr}25 & 18 & 9 & 25 \\ 67 & 59 & 43 & 71\end{array}$

$\begin{array}{rrrr}25 & 18 & 9 & 25 \\ 67 & 59 & 43 & 71\end{array}$

Muy interesante 5

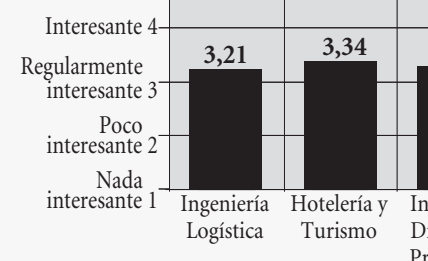$$
\text { Bogot: }
$$

Bogotá 3.25

Cali 3.33

3.37

3.29

3.37

3.49

2.84

3.27

2.88

2.42

Barranquilla 2.85

3.62

2.76

2.59

Cartagena 2.64

3.28

3.09

2.55

Base : Total de personas que piensan adelantar $\mathrm{o}$ continuar sus estudios. $\mathrm{n}=1384$ 


\section{Gráfica 17. Programa preferido en general -Razones- \%}

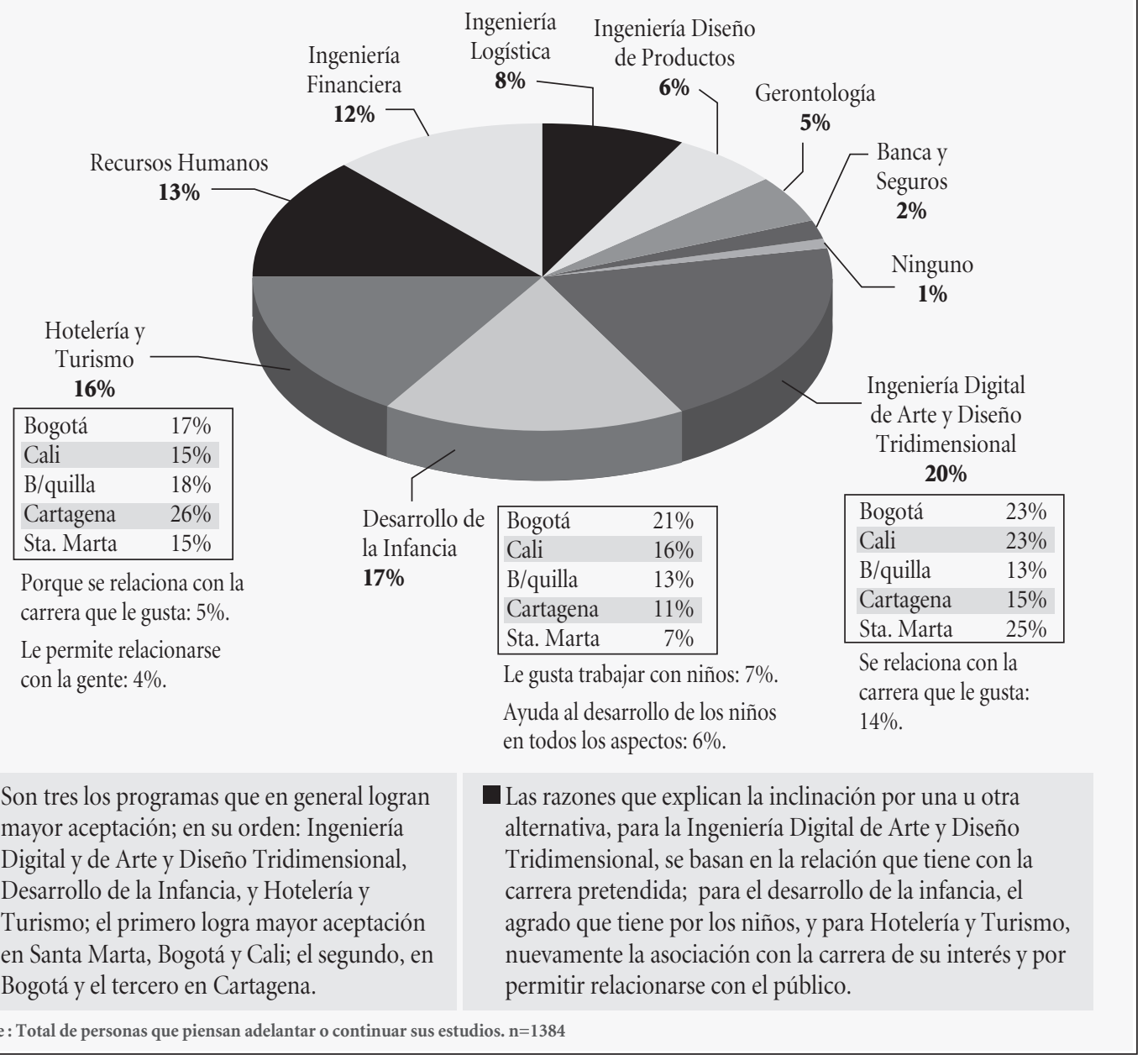

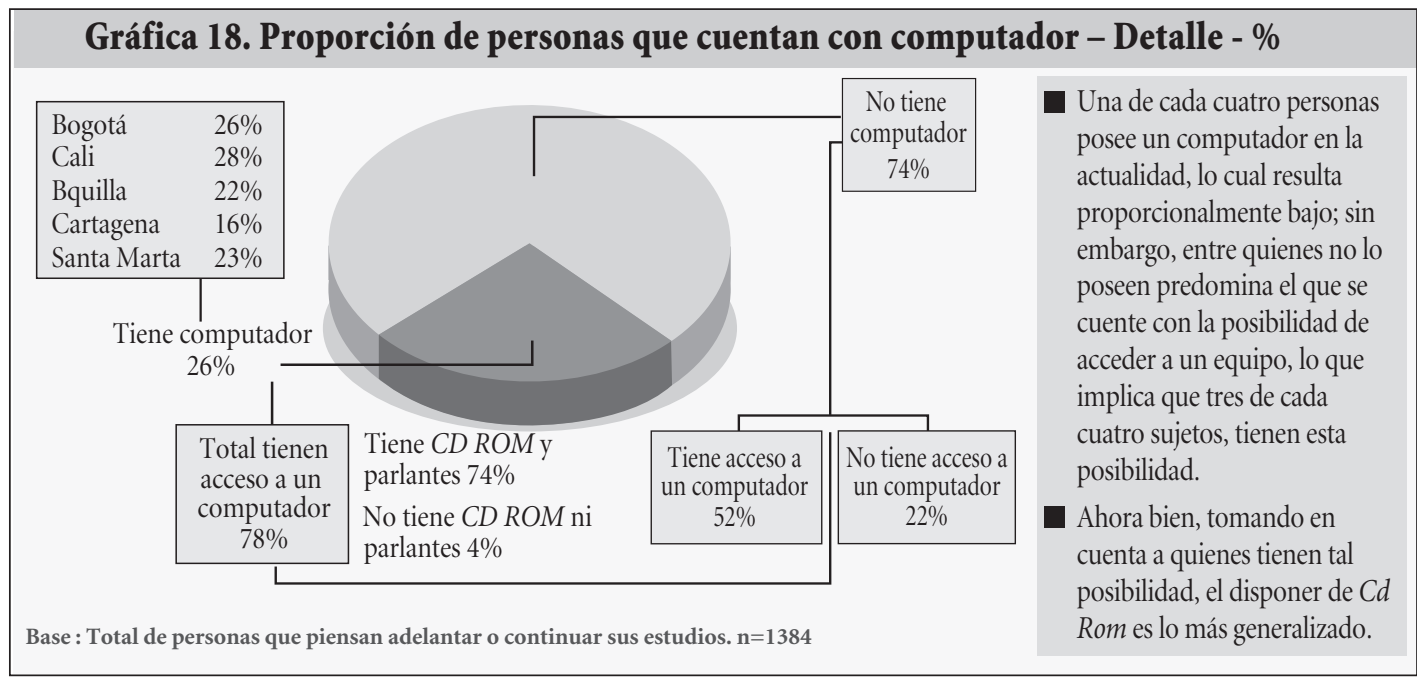




\section{Gráfica 19. Proporción de personas que tienen acceso a internet - Detalle - \%}

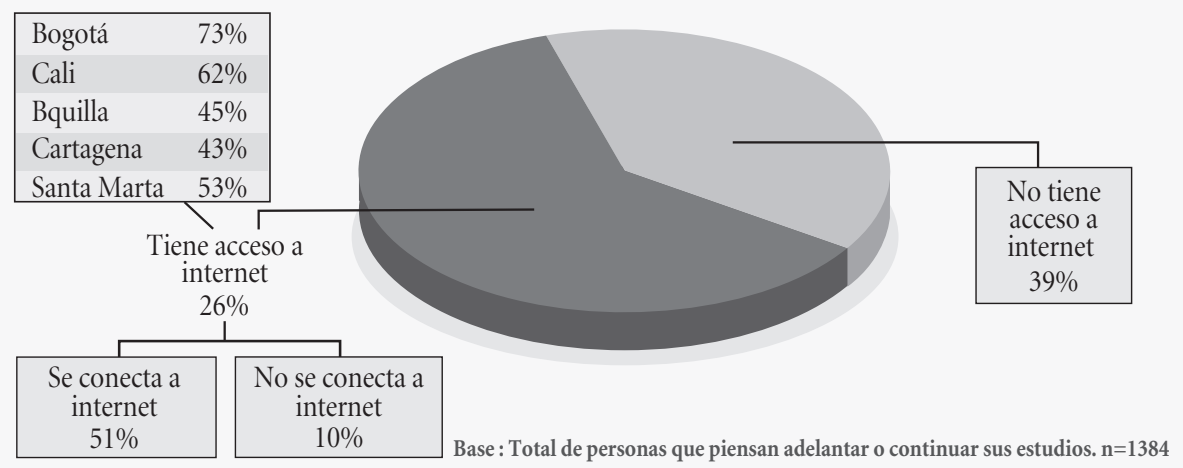

A pesar de no ser frecuente contar con un equipo propio, la posibilidad de conectarse a internet es significativa, aunque solo la mitad de la población general hace empleo de este medio de comunicación.
Bogotá y Cali, en su orden, superan de manera amplia a las demás ciudades y más aun a las poblaciones.

Tabla 4. Mercado potencial

\begin{tabular}{|c|c|c|c|c|c|c|c|}
\hline ZONAS & \multicolumn{2}{|c|}{ CENTRO } & \multicolumn{2}{|c|}{ OCCIDENTE } & \multicolumn{2}{|c|}{ COSTA } & \multirow{8}{*}{$\begin{array}{l}\text { Independientemente de las } \\
\text { actividades de mercadeo que } \\
\text { se propongan para difundir el } \\
\text { programa y adelantando un } \\
\text { proceso en el que se eliminan } \\
\text { aquellas personas que se } \\
\text { muestran reacias al proyecto o } \\
\text { que tienen limitaciones para } \\
\text { participar en él, la zona } \\
\text { Centro es, sin lugar a dudas, } \\
\text { la que ofrece mayor potencial, } \\
\text { beneficiada obviamente por el } \\
\text { peso poblacional de Bogotá. }\end{array}$} \\
\hline & $\%$ & $\mathbf{n}$ & $\%$ & $\mathbf{n}$ & $\%$ & n & \\
\hline POBLACIÓN ESTIMADA AÑO 2003 & 100 & $8^{\prime} 208.569$ & 100 & 3'968.480 & 100 & $2^{\prime} 768.457$ & \\
\hline${ }^{*}$ CAPITALES & 85 & $6^{\prime} 958.815$ & 58 & $2^{\prime} 321.426$ & 100 & $2^{\prime} 768.457$ & \\
\hline * CABECERAS & 15 & $1^{\prime} 249.754$ & 42 & $1^{\prime} 647.044$ & 0 & 0 & \\
\hline \begin{tabular}{|l|} 
PERSONAS DE LOS ESTRATOS 2 A 4 - \\
PARA CAPITALES Y TOTAL CABECERA \\
EN EDADES ENTRE LOS 16 Y 45 AÑOS \\
\end{tabular} & 56 & 4'596.799 & 56 & $2^{\prime} 222.349$ & 38 & 1'052.014 & \\
\hline $\begin{array}{l}\text { ESTUDIANTES COLEGIO GRADOS 10-11, } \\
\text { TÉCNICOS / TECNÓLOGOS COMPLETOS } \\
\text { E INCOMPLETOS }\end{array}$ & 74 & 3'401.163 & 87 & 1'933.443 & 91 & 957.332 & \\
\hline TIENEN PREVISTO ESTUDIAR & 66 & $2^{\prime} 245.076$ & 88 & $1^{\prime} 701.430$ & 95 & 909.466 & \\
\hline $\begin{array}{l}\text { TIENEN COMPUTADOR CON CD ROM + } \\
\text { PARLANTES O ACCESO A ÉL }\end{array}$ & 84 & $1^{\prime} 885.864$ & 78 & 1'327.116 & 82 & 745.762 & $\begin{array}{l}\text { En un segundo plano aparece } \\
\text { el Valle, mientras que la costa }\end{array}$ \\
\hline INTERÉS POR EDUCACIÓN A DISTANCIA & 42 & 792.063 & 42 & 557.389 & 49 & 365.423 & interés. \\
\hline * 100\% DE TOTALMENTE INTERESADOS & 21 & 396.031 & 19 & 252.152 & 28 & 208.813 & \\
\hline$* 40 \%$ DE INTERESADOS & 21 & 396.031 & 23 & 305.237 & 21 & 156.610 & \\
\hline
\end{tabular}


Tabla 5. Interés neto por programas

\begin{tabular}{|c|c|c|c|}
\hline \multicolumn{3}{|c|}{ PROGRAMAS PROPUESTOS } & \multirow[b]{2}{*}{ COSTA } \\
\hline ZONAS & CENTRO & OCCIDENTE & \\
\hline * INGENIERÍA LOGÍSTICA & 142.670 & 156.362 & 83.051 \\
\hline * HOTELERÍA Y TURISMO & 403.411 & 182.422 & 177.175 \\
\hline $\begin{array}{r}* \text { INGENIERÍA DISEÑO DE } \\
\text { PRODUCTOS }\end{array}$ & 132.831 & 114.665 & 52.599 \\
\hline * GERONTOLOGÍAS & 88.514 & 99.029 & 38.757 \\
\hline * DESARROLLO DE LA INFANCIA & 413.250 & 239.754 & 96.893 \\
\hline $\begin{array}{l}\text { * INGENIERÍA DIGITAL DE ARTE Y } \\
\text { DISEÑO TRIDIMENSIONAL }\end{array}$ & 423.089 & 260.602 & 157.796 \\
\hline * INGENIERÍA FINANCIERA & 226.304 & 239.754 & 171.639 \\
\hline * BANCA Y SEGUROS & 54.117 & 26.06 & 13.842 \\
\hline * RECURSOS HUMANOS & 236.143 & 239.754 & 116.271 \\
\hline
\end{tabular}

\section{CONCLUSIONES DEL ESTUDIO}

- 76\% de la población ha cursado un nivel apto para ser considerado parte del potencial del mercado.

- Tan solo 3\% de la población ha alcanzado un título mediante la modalidad de educación a distancia.

- La participación de entidades públicas y privadas es similar, teniendo en cuenta las características de la población.

- $16 \%$ de las personas del target se encuentra estudiando en la actualidad, sin embargo, $88 \%$ aspira a iniciar y/o continuar los estudios.

- La orientación de las carreras que se pretende adelantar, se acentúa en la línea de sistemas, bien sea como ingenierías o como tecnologías. Acceder a ellas está sujeto al logro de planes de financiación y a precios bajos en las matrículas.
- El principal elemento inhibidor para adelantar un programa de educación superior ha sido el factor económico (62\%), que supera las limitantes de tiempo (21\%).

- La modalidad educación a distancia es conocida por el $52 \%$ de la población; crece su difusión en ciudades menores.

- Poder estudiar en casa (29\%) y contar con material de estudio (26\%), son los dos aspectos que definen principalmente la educación a distancia.

- Desarrollarse laboralmente de manera paralela (24\%), ahorrar tiempo (20\%) y estudiar sin salir de casa (18\%), son los reconocimientos que se hacen a esta modalidad.

- Por el contrario, se cuestiona y de manera repetitiva, no contar con una persona que resuelva dudas.

- No existe claridad respecto al título que se puede obtener bajo esta modalidad. 
- Tres de cada cuatro personas se muestran positivas ante la posibilidad de adelantar los estudios en la modalidad; sin embargo, son más favorables las respuestas en las ciudades costeras, así como en Fusa y Girardot, donde se hace evidente la distancia respecto a las ciudades capitales de mayor importancia.

- Independientemente de si terminó el programa o no, $7 \%$ de la población ha tenido contacto con la educación a distancia.

- A partir de la presentación del concepto descriptivo del proyecto, en la totalidad de los casos se le asocian aspectos positivos como poder estudiar desde cualquier lugar (34\%); aunque la debilidad del proyecto se centra en la carencia de un computador (30\%).

- El interés manifestado por el programa es positivo aunque susceptible de ser mejorado; Cartagena, a este respecto, refleja una mejor disposición mientras Cali y Barranquilla son las ciudades más severas.

- Nuevamente se hace referencia a contar con un plan de crédito como el motivador para cursar programas como los presentados (53\%).

- El interés por un programa en particular tanto en lo personal como regional se centra en la línea de sistemas.

- La importancia que se concede a los programas propuestos varía entre las ciudades o poblaciones (ver tabla 6. 1 es la calificación más alta y 4 la más baja):

- La orientación profesional se da en mayor grado en estos programas, con diferencia importante sobre la técnica y la tecnológica.

- En orden de importancia, la preferencia general apunta a Ingeniería Digital de Arte y Diseño Tridimensional, Desarrollo de la Infancia y Hotelería y Turismo, respondiendo al cuadro anteriormente presentado.

Tabla 6. Importancia de programas por ciudad

\begin{tabular}{|c|c|c|c|c|c|c|c|c|c|c|}
\hline & $\begin{array}{l}\text { 近 } \\
0 \\
0 \\
0 \\
0\end{array}$ & ఫે & 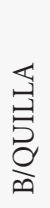 & 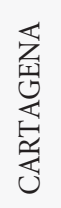 & 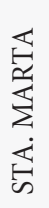 & 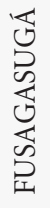 & 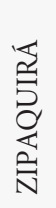 & 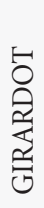 & 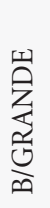 & 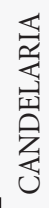 \\
\hline Ingeniería Logística & & & & & & & 3 & & 3 & \\
\hline Hotelería y Turismo & & 2 & 2 & 1 & 2 & 2 & & 1 & & \\
\hline Ingeniería de Diseño de Producto & & & & & & & & & & 3 \\
\hline \multicolumn{11}{|l|}{ Gerontología } \\
\hline Desarrollo de la Infancia & 3 & & & & & 1 & 2 & 2 & 1 & 2 \\
\hline $\begin{array}{c}\text { Ingeniería Digital de Arte y Diseño } \\
\text { Tridimensional }\end{array}$ & 1 & & & & 1 & 3 & 1 & 3 & & 1 \\
\hline Ingeniería Financiera & & 3 & 3 & 3 & & & & & 2 & \\
\hline \multicolumn{11}{|l|}{ Banca y Seguros } \\
\hline Recursos Humanos & 2 & 1 & 1 & 2 & 3 & & & & & \\
\hline
\end{tabular}


- $29 \%$ de la población sabe de la existencia del Politécnico Grancolombiano (limitado a Bogotá y, en alguna medida, a Cali); en este grupo la imagen que la entidad posee es altamente favorable de la que se destaca el nivel académico.

- En esta línea, se valora positivamente la posibilidad de ser el Politécnico quien respalde el proyecto presentado.

- Respecto al computador, ser propio (26\%) o acceder a él (52\%), establece un potencial importante de desarrollo del proyecto.

- El 61\% cuenta con la posibilidad de conectarse a internet. El 10\% que lo puede hacer, nunca lo hace.

- En proporciones similares, en el público se encuentran personas solteras y personas con una relación de pareja.

- La mitad de la población tiene hijos (1.67 en promedio).

- Es importante la proporción de quienes trabajan los sábados e incluso los domingos.

- El potencial del mercado más alto sin tener en cuenta si conoce o no el Politécnico Grancolombiano, se da en la región Centro, seguido por la región Occidente:
- Centro. 800.000
- Occidente
- Norte 360.000

\section{CONCLUSIONES}

- Aunque el número de personas que responde a las características básicas de la población es un potencial importante, al contemplar las actitudes y recursos disponibles, este potencial desciende considerablemente.

- Bogotá es la plaza que ofrece mayor atractivo (800.000 personas), seguida de Cali (180.000) en correspondencia con la estructura actual del mercado.
- En principio, son estas las dos regiones que deben desarrollarse, porque además tienen un mayor conocimiento del Politécnico Grancolombiano como una entidad de respaldo.

- Es necesario comunicar las posibilidades de título que se ofrece, en razón del marcado desconocimiento de las tres opciones: técnico, tecnólogo y profesional. Implica hacer claridad en la posibilidad de alcanzar un título por cada nivel.

- Los beneficios sobre los cuales deben girar las estrategias de comunicación son, indudablemente, el manejo de tiempo y el menor costo comparativo con una modalidad presencial.

- De los posibles programas para ser implementados ganan en importancia:

- Recursos humanos: Bogotá, Cali, Barranquilla, Cartagena y Santa Marta.

- Ingeniería Digital de Artey Diseño: Bogotá, Santa Marta, Zipaquirá y Candelaria

- Desarrollo de la infancia: para poblaciones menores.

- Hotelería y Turismo: Cali, las tres ciudades costeras, Fusagasugá y Girardot.

- Sin embargo es necesario tener en cuenta el atractivo que espontáneamente adquieren los sistemas, bien sea como carrera profesional o como tecnológica, y se convierten, por ende, en una excelente alternativa de desarrollo.

- El ofrecimiento de la modalidad debe estar asociado de manera clara con las posibilidades de financiación, aspecto determinante para la decisión final.

- Finalmente, teniendo en cuenta las apreciaciones de quienes ya participan en el mercado, es determinante preparar un cuerpo docente especializado que conozca el proceso y que ofrezca apoyo personalizado.

El tema principal de indagación se resume en la tabla 7, como recomendación 
última de programas para ser desarrollados por el Politécnico Grancolombiano bajo la modalidad de educación a distancia en ambientes virtuales de aprendizaje:

\section{Tabla 7. Tema principal de indagación}

\begin{tabular}{|c|c|c|c|c|}
\hline $\begin{array}{c}\text { Región/ } \\
\text { Temática }\end{array}$ & $\begin{array}{c}\text { Recursos } \\
\text { Humanos }\end{array}$ & $\begin{array}{c}\text { Ingeniería } \\
\text { Digital Arte } \\
\text { y Diseño } \\
\text { Tridimen- } \\
\text { sional }\end{array}$ & $\begin{array}{c}\text { Desarrollo } \\
\text { de la } \\
\text { Infancia }\end{array}$ & $\begin{array}{c}\text { Hotelería y } \\
\text { Turismo }\end{array}$ \\
\cline { 1 - 1 } Centro & \multirow{2}{*}{$\mathrm{X}$} & $\mathrm{X}$ & $\begin{array}{c}\text { Poblacio- } \\
\text { nes menores }\end{array}$ & \\
\cline { 1 - 1 } Occidente & & & $\mathrm{X}$ \\
\cline { 1 - 1 } Caribe & & & & \\
\hline
\end{tabular}

En este orden de ideas, se tomó la decisión de retirar las variantes región andina - eje cafetero, por ser una de las regiones con mayor oferta de programas a distancia y se seleccionaron los siguientes programas con miras a la obtención de registro calificado:

\section{INGENIERÍA EN MEDIOS DIGITALES}

Pensar en un programa de Ingeniería en Medios Digitales, nuevamente nos ubica en el desarrollo de la tecnología, pero esta vez aplicada al arte por medio de las imágenes, la música, el diseño, la creatividad, a cualquier ciencia, a la educación y a la economía. Desde esta mirada, la tecnología no solo aporta una gran combinación multimedia que permite al usuario incursionar creativamente hasta donde su imaginación lo permite, sino que además lo introduce en las realidades virtuales que se plasman en una multiplicidad de sistemas, y le permiten hacer cosas realmente especiales a través de un medio esencialmente activo. Al mismo tiempo, logra que la imaginación y la crea- tividad tengan la posibilidad de generar un micromundo artificial e ilimitado.

Aunque su campo de acción es muy amplio, Colombia no ha incursionado realmente en él, tal y como lo requiere el futuro inmediato en la aplicación de áreas tales como la medicina, la arquitectura, las ingenierías, la biogenética, en fin, en cualquier ciencia, arte o disciplina que involucre en sus procesos investigativos, la creación de micromundos.

\section{ADMINISTRACIÓN HOTELERAY TURISIIICA}

El sector del turismo tiene significación económica, tanto por las divisas como por el empleo que genera. Según la World Travel Tourism Council WTTC, "para 1996 se contabilizaban 255.4 millones de empleos en el sector turístico, cifra que representa el $10.7 \%$ del total de empleos mundiales. Frente a dicho porcentaje y mejor aún al de 1993, cuando el sector participó con el 10.2\%, Colombia reportó el 6.25\%, mientras Estados Unidos el 11.1\% y México el 10.3\%”. En los últimos años, el turismo receptor internacional ha venido aumentando su participación notoriamente en la región latinoamericana y caribeña, debido al crecimiento sostenido mundial del sector.

No obstante la situación social y política que vive el país, existe un marco legal y unas políticas coherentes que involucran todos los aspectos necesarios para el estímulo del sector. Por ejemplo, la Ley de Turismo contempla el fomento de diferentes tipos de turismo, relacionados con el medio ambiente como el ecoturismo, que busca un desarrollo sostenible, ético, estético, económico, social, cultural y educativo, además de contemplar una amplia gama 
de empresas que, por sus características, se incluyen en este ámbito como son: hoteles, agencias de viaje, transporte, restaurantes, representaciones turísticas, fincas, operadores de congresos, turismo social, ecoturismo, institutos de formación, prepago.

Además, el Estudio de Competitividad de Turismo Colombiano para el Mercado Internacional, presenta una división de clusters turísticos para el país, al tiempo que le define las estrategias para su desarrollo y las acciones que posibilitarían elevar el atractivo de los mismos, teniendo como base las tendencias del mercado turístico internacional yla influencia en el producto turístico colombiano. Las iniciativas anteriores son posibles en la medida en que se cuente con personal formado y calificado en los diferentes subsectores que integran el sector turístico del país, tarea que le compete al sistema educativo y en este caso, a las instituciones de educación superior.

\section{ADMINISTRACIÓN DE RECURSOS HUMANOS}

La disciplina de la gestión integrada de los recursos humanos, está experimentando cambios muy significativos que le exigen el estudio y la profundización en esta disciplina, a partir de procesos investigativos en las ciencias que la soportan. Actualmente, el área de recursos humanos propende por el estudio de estos cambios y por el análisis acerca de cómo las empresas los están incorporando a sus sistemas de gestión; los nuevos sistemas de gestión por competencias, los recursos humanos en organizaciones basadas en el conocimiento y las mejores prácticas de gestión en planificación, selección, formación, desarrollo, gestión del desempeño, retribución.

Igualmente, el desarrollo de habilidades directivas exige el perfeccionamiento de competencias personales, como el auto- control, la autoconfianza, la capacidad de dirigir personas y equipos, el liderazgo, la capacidad de trabajar en equipo, la empatía, la persuasión, la comunicación y la capacidad de negociación.

La óptica anterior exige pensar en diseñar programas educativos especializados alrededor de los recursos humanos, pues los temas antes mencionados no se pueden seguir contemplando en la perspectiva de pequeñas acciones de capacitación que no permiten una mirada holística del desarrollo del talento humano en la empresa, sin menoscabo de la educación no formal.

\section{ADMINISTRACIÓN EN DESARROLLO DE LA INFANCIA}

Tanto en el campo internacional como el nacional, los lineamientos generales de la política de salud y desarrollo social se orientan hacia actividades que permitan garantizar mejores condiciones de desarrollo individual y colectivo de la sociedad, en cuanto que es a partir de allí como se definen los primeros factores relacionados con la calidad de vida de las personas $y$, por ende, de la sociedad. El niño, actor primordial en cualquier sociedad, requiere unas condiciones de vida mínimas, desde el momento mismo en que es engendrado, hasta que llega a su juventud, puesto que incidir en los factores que regulan sus comportamientos y actitudes es intervenir directamente en una serie de factores de equidad y desarrollo que, encadenados, actúan en el capital humano y lo potencian para el desarrollo de un país. Son estas algunas de las razones que conducen a diferentes países e instituciones educativas a desarrollar programas educativos en esta área, y más si se tiene en cuenta que el factor humano es, en la actualidad, el recurso más valioso de una empresa y de una sociedad. 


\section{BIBLIOGRAFÍA}

- Ministerio de Trabajo y Seguridad Social (2004). Boletín comportamiento del mercado de trabajo. Bogotá.

- Ministerio de Educación Nacional (2004). Sistema Nacional de Información de la Educación Superior-SNIES. Bogotá.

- Ministerio de Trabajo y Seguridad Social y SENA (1998). Clasificación Nacional de Ocupaciones. Bogotá.

- Politécnico Grancolombiano (2004). PEI, documento de trabajo. Bogotá.

- Fedesarrollo (1998). Demanda de recursos humanos en sectores productivos estratégicos. Informe investigativo. Santafé de Bogotá.

- Sena (1998). Indicadores del mercado laboral. Santafé de Bogotá: Grupo de publicaciones del Sena.

- Sena (1999). Estudio de caracterización de la logística en Colombia. Mesa sectorial de logística. Santafé de Bogotá: Editorial Precolombi.
- Sena (1999). Estudio de caracterización del mercadeo. Santafé de Bogotá: Editorial Precolombi.

- Sena (2000). Estudio de caracterización ocupacional del sector fibras, textil, confección en Colombia. Santafé de Bogotá: Editorial Grupo de Publicaciones Sena, Dirección General.

- Sena (2001). Caracterización del sector salud. Bogotá: Editorial Grupo de Publicaciones Sena, Dirección General.

- Sena (2000). Estudio de caracterización ocupacional del sector de servicios financieros. Santafé de Bogota: Editorial Grupo de Publicaciones Sena, Dirección General.

- Sena (2002). Caracterización ocupacional de las telecomunicaciones en Colombia. Bogotá: Editorial Grupo de Publicaciones Sena, Dirección General.

- Sena (1999). Caracterización Sectorial de Turismo en Colombia. Bogotá: Mimeo.

\section{PÁGINASWEB CONSULTADAS}

- www.mineducacion.edu.co

- www.tendenciasinternacionalesenlaeducacioneningenierias

- www.urosario.edu.co

- wwwl.universia.net/CatalogaXXI/default. asp?IDC=10032\&IDP=ES\&IDI

- www.usfq.edu.ec

- www.fit.edu

- www.uistmo.edu/

- www.escuelaing.edu.co

- www.audrey-cohen.edu/

- www.ciis.edu/

- www.ucm.es/

- www.deusto.es

- www.fu-berlin.de

- www.asfh-berlin.de
- www.fh-magdeburg.de

- www.hfbk-dresden.de

- www.ph-heidelberg

- www.u-picardie.fr

- www.univ-paris1.fr/

- www.education.gouv.fr

- www.colombiacompite.gov.co

- www.agrocadenas.gov.co .

- www.colombiacompite.gov.co

- www.unad.gov.co

- www.uned.es

- www.ie.edu/ie/claustro_e_investigacion/ claustro/catedrasM.htm

- www.infoexport.copca.com/.docs/copca/ textcol.pdf

- www.textil-confeccion.com.co/html/articulos/alca1-1.htm 
- www.textil-confeccion.com.co/html/articulos/articulos1_1.htm

- www.upc.es/3er-cicle/cas/doctorat/programes/53.htm

- www.polinal.edu.co

- www.unad.edu.co

- www.ucn.edu.co

- www.usta.edu.co

- www.ceipa.edu.co

- www.iafic.edu.co

- www.funlam.edu.co

- www.unicartagena.edu.co

- www.pascualbravo.edu.co

- www.uptc.edu.co

- www.politecjic.edu.co

- www.autonoma.edu.co

- www.tdea.edu.co

- www.ucatolicamz.edu.co

- www.uco.edu.co

- www.ucaldas.edu.co

- www.udea.edu.co

- www.uniamazonia.edu.co

- www.usb.edu.co

- www.uniamazonia.edu.co

- www.upb.edu.co

- www.unisabana.edu.co

- www.uac.edu.co

- www.usco.edu.co

- www.cun.edu.co
- www.uniguajira.edu.co

- www.udca.edu.co

- www.unimag.edu.co

- www.ean.edu.co

- www.unimag.edu.co

- www.esap.edu.co

- www.udenar.edu.co

- www.eurocol.edu.co

- www.umariana.edu.co

- www.areandina.edu.co

- www.fesc.edu.co

- www.ulibertadores.edu.co

- www.unipamplona.edu.co

- www.javeriana.edu.co

- www.ufps.edu.co

- www.unionamericana.edu.co

- www.uniquindio.edu.co

- www.uanarino.edu.co

- www.ucpr.edu.co

- www.usb.edu.co

- www.centrosisremas.edu.co

- www.udistrital.edu.co

- www.unab.edu.co

- www.unbosque.edu.co

- www.uis.edu.co

- www.umng.edu.co

- www.utolima.edu.co

- www.uvalle.edu.co 